\title{
13.1
}

\section{Особенности применения электронов в исследовании пленок гексаферрита бария на $c$-сапфире}

\author{
(c) А.Э. Муслимов ${ }^{1}$, М.Г. Исмаилов ${ }^{2}$, В.М. Каневский ${ }^{1}$ \\ ${ }^{1}$ Федеральный научно-исследовательский центр „Кристаллография и фотоника“ РАН, Москва, Россия \\ ${ }^{2}$ Дагестанский государственный университет, Махачкала, Россия \\ E-mail: amuslimov@mail.ru
}

Поступило в Редакцию 14 июля 2020г.

В окончательной редакции 21 сентября 2020 r.

Принято к публикации 22 сентября 2020 г.

\begin{abstract}
Исследованы процессы формирования пленок (0001) $\mathrm{BaFe}_{12} \mathrm{O}_{19}$ на сапфире с ферромагнитной „легкой осью“, направленной вдоль нормали к подложке. Изучено распространение пучка высокоэнергетических электронов в процессе взаимодействия с пленкой $(0001) \mathrm{BaFe}_{12} \mathrm{O}_{19}$ в зависимости от угла падения пучка. Продемонстрировано отклонение скользящего пучка электронов магнитным полем пленки $(0001) \mathrm{BaFe}_{12} \mathrm{O}_{19}$. Показано, что присутствие пленки (0001) $\mathrm{BaFe}_{12} \mathrm{O}_{19}$ на сапфире приводит к перераспределению катодолюминесценции в нем преимущественно в „красную“ область. Излучения, связанного с самой пленкой, в эксперименте не обнаружено.
\end{abstract}

Ключевые слова: гексаферрит бария, сапфир, электроны, люминесценция.

DOI: 10.21883/PJTF.2021.01.50455.18465

Среди стремительно развивающихся направлений науки и техники, которые могут внести существенный вклад в развитие современной электроники, наиболее перспективным является спинтроника. В основе спинтроники лежат всевозможные способы создания и управления спин-поляризованными токами. Наиболее простым способом формирования спин-поляризованного тока является пропускание электрического тока через ферромагнетик, помещенный в магнитное поле, с последующей инжекцией этого тока в обычный проводник. В соответствии с высокими требованиями к энергоэффективности электронных устройств оптимально использование внутреннего магнитного поля анизотропного ферромагнетика. Одним из таких ферромагнетиков является гексаферрит бария $\left(\mathrm{BaFe}_{12} \mathrm{O}_{19}\right) \quad M$-типа, обладающий уникальным сочетанием свойств: высокая температура Кюри (около $450^{\circ} \mathrm{C}$ ), большая намагниченность насыщения (64-70 emu $/ \mathrm{g})$, магнитная энергия до $34 \mathrm{~kJ} / \mathrm{m}^{3}$, устойчивость к размагничиванию и химическая инертность к агрессивным средам. Несмотря на широкое применение [1-8], практически неизученными остаются вопросы взаимодействия потока заряженных частиц с пленками $\mathrm{BaFe}_{12} \mathrm{O}_{19}$. Ферромагнитные пленки $\mathrm{BaFe}_{12} \mathrm{O}_{19}$ характеризуются магнитной анизотропией типа „легкая ось“, направленной нормально к плоскости пленки. В зависимости от направления распространения пучка электронов относительно плоскости пленки возможно как их проникновение в нее, так и отклонение под действием лоренцевой силы. Следует заметить, что проблемой отклонения и фокусировки пучков заряженных частиц с использованием кристаллов занимаются давно. Аналогичные исследования с использованием пленок $\mathrm{BaFe}_{12} \mathrm{O}_{19}$ представляют не только прикладной, но и фундаментальный интерес. В настоящей работе изучено распространение пучка высокоэнергетических электронов в процессе взаимодействия с ферромагнитной пленкой $\mathrm{BaFe}_{12} \mathrm{O}_{19}$, полученной на $c$-сапфире.

Образцы сапфировых пластин базисной $(c)$ ориентации собственного производства полировались (двусторонняя полировка) химико-механическим способом до значения шероховатости $0.2 \mathrm{~nm}[9,10]$. Далее на подложки сапфира при температуре $350^{\circ} \mathrm{C}$ наносились пленки $\mathrm{BaFe}_{12} \mathrm{O}_{19}$ методом магнетронного напыления из керамической мишени в атмосфере аргона $\left(p_{\mathrm{Ar}} \sim 5.6 \cdot 10^{-3}\right.$ Torr $)$ в течение $30 \mathrm{~min}$. Поскольку $\mathrm{Al}$-замещенные пленки $\mathrm{BaFe}_{12} \mathrm{O}_{19}$ имеют более высокое значение магнитокристаллической анизотропии, использовалась мишень, содержащая алюминий в качестве примеси. Для микроскопических исследований применялся настольный растровый электронный микроскоп ЈСМ-6000, оснащенный приставкой для проведения энергодисперсионного микроанализа. Состав керамической мишени по данным энергодисперсионного

Элементный состав керамической мишени $\mathrm{BaFe}_{12} \mathrm{O}_{19}$ по данным энергодисперсионного микроанализа

\begin{tabular}{c|c|c}
\hline \multirow{2}{*}{ Элемент } & \multicolumn{2}{|c}{ Содержание } \\
\cline { 2 - 3 } & at.\% & mass\% \\
\hline $\mathrm{O}$ & 44 & 16.91 \\
$\mathrm{Al}$ & 1.29 & 0.83 \\
$\mathrm{Ba}$ & 4.52 & 14.90 \\
$\mathrm{Fe}$ & 49.69 & 66.65 \\
$\mathrm{Si}$ & 0.33 & 0.22 \\
$\mathrm{Sn}$ & 0.17 & 0.49
\end{tabular}




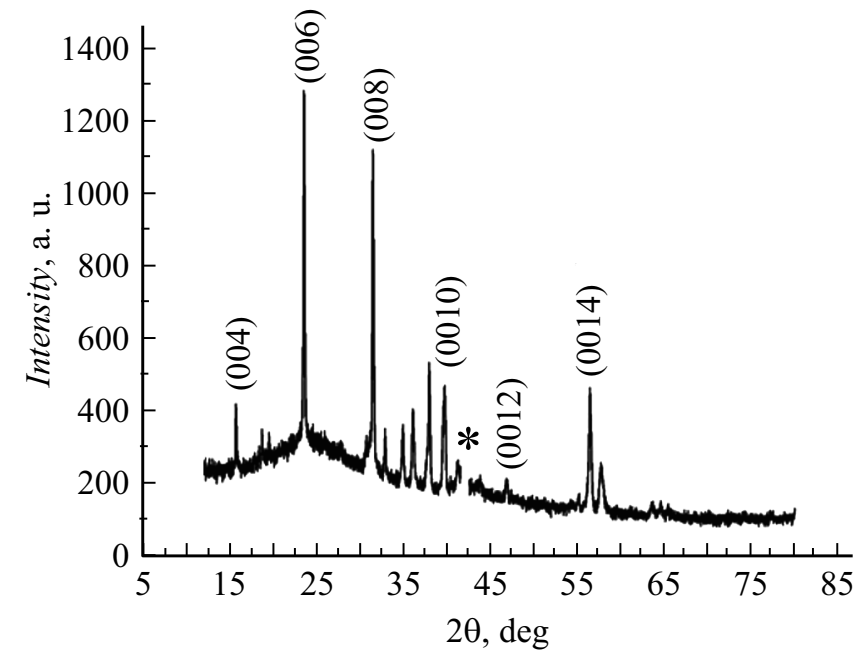

Рис. 1. Рентгеновская дифракция пленки $\mathrm{BaFe}_{12} \mathrm{O}_{19}$ на сапфире после этапа постростового отжига в атмосферных условиях при температуре $1000^{\circ} \mathrm{C}$. Звездочкой обозначен рефлекс подложки $c$-сапфира.

микроанализа представлен в таблице. Рентгеновские исследования проводились на дифрактометре X'PERTPRO (PANalytical, Нидерланды) в геометрии „на отражение“ по Брэггу-Брентано на излучении $\mathrm{Cu}_{\alpha}(\lambda=1.54 \AA)$ с $\beta$-фильтром Ni. По данным рентгеновской дифракции первоначально пленки $\mathrm{BaFe}_{12} \mathrm{O}_{19}$ толщиной $\sim 500 \mathrm{~nm}$ формировались в виде аморфного осадка. Для текстурирования пленок $\mathrm{BaFe}_{12} \mathrm{O}_{19}$ (рис. 1) вдоль [0001] применялся этап постростового отжига в атмосферных условиях при температуре $1000^{\circ} \mathrm{C}$.

Электронографические исследования пленки проводились в геометрии на отражение (горизонтальный электронограф, ускоряющее напряжение $75 \mathrm{kV}$ ) с использованием скользящего пучка электронов. Исследование спектров излучения осуществлялось при возбуждении катодолюминесценции (КЛ) в пленках электронным пучком электронографа (угол между пучком электронов и нормалью к плоскости пленки $45^{\circ}$ ). Исследования КЛ проводились в трех режимах. В режиме I исследовалась КЛ образца подложки сапфира. Далее исследования образца пленки $\mathrm{BaFe}_{12} \mathrm{O}_{19}$ на сапфире осуществлялись при возбуждении потоком электронов со стороны пленки с ускоряющими напряжениями 40 и $70 \mathrm{kV}$. При этом использовалось две конфигурации входной группы спектрометра: в режиме II группа располагалась со стороны пленки $\mathrm{BaFe}_{12} \mathrm{O}_{19}$; в режиме III группа располагалась со стороны подложки. В режимах II и III входная группа спектрометра устанавливалась в положениях, симметричных относительно плоскости подложки. Использовались потоки электронов с эллиптическим пятном на образце размером $3 \mathrm{~mm}$ и круглым (фокусированным) размером $0.5 \mathrm{~mm}$.

Картина, полученная с использованием метода дифракции быстрых электронов от пленки $\mathrm{BaFe}_{12} \mathrm{O}_{19}$ на c-сапфире, представлена на рис. 2, $a$. На картине присутствуют центральное пятно слабой интенсивности, кольца, увеличенное в диаметре пятно свечения, смещенное вправо относительно центральной оси дифракционной картины. Отсутствие типичной дифракционной картины с явным смещением изображения в один из секторов фотопластинки свидетельствует о декогерентном воздействии магнитного поля пленки на падающий пучок электронов.

В спектрах КЛ, отснятых во всех трех режимах, с той или иной степенью интенсивности представлены три основные полосы: полоса с максимумом при $330 \mathrm{~nm}$, узкий пик при $694 \mathrm{~nm}$, широкая полоса в области 600-1050 nm. В спектре КЛ (рис. 2, b) подложки сапфира (режим I, кривые 1,2) наблюдаются все указанные полосы. При увеличении ускоряющего напряжения от 40 до $70 \mathrm{kV}$ происходит как усиление, так и выравнивание интенсивностей свечения полос в ультрафиолетовой и длинноволновой областях. Помимо этого при ускоряю-
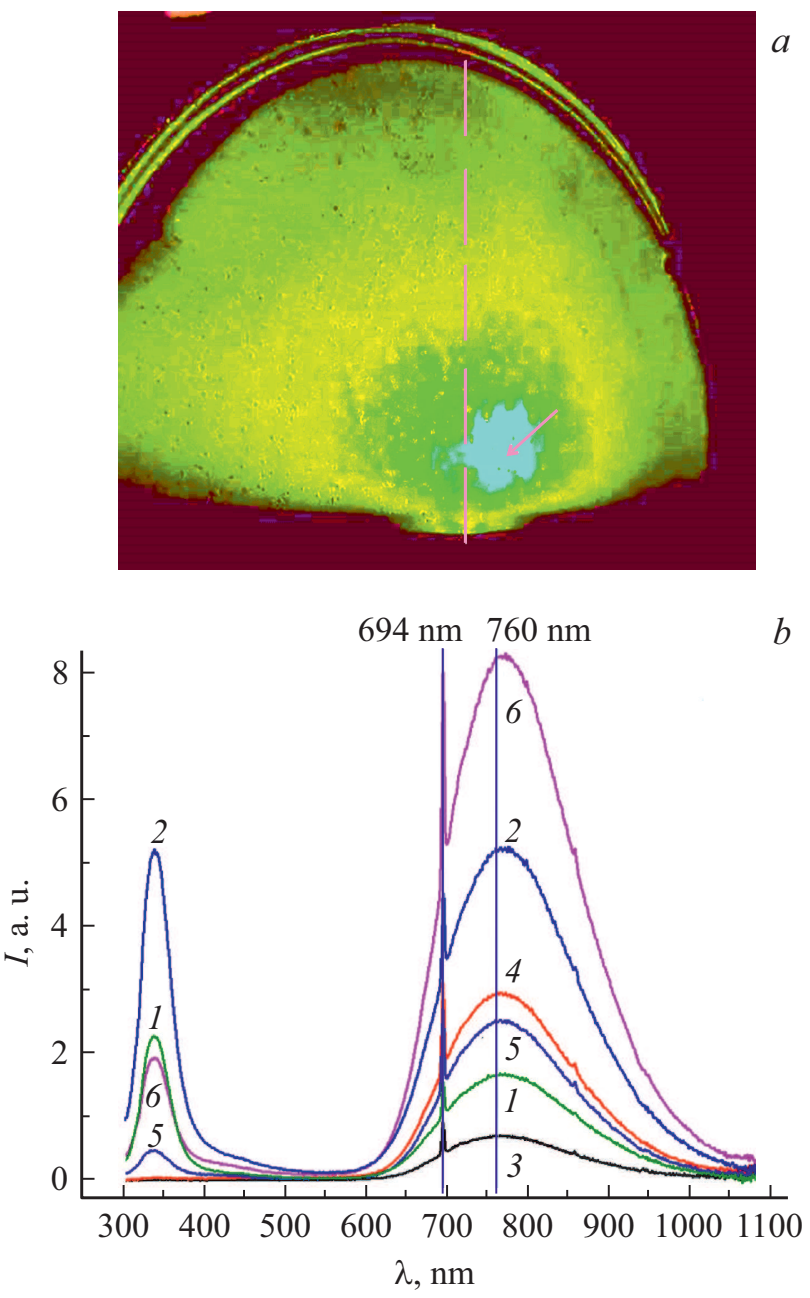

Рис. 2. Картина отклонения пучка электронов пленкой $\mathrm{BaFe}_{12} \mathrm{O}_{19}(a)$ и спектральная зависимость катодолюминесценции пленок $(b)$ гексаферрита бария на $c$-сапфире. Режим I: $1-$ $40 \mathrm{kV}, 2-70 \mathrm{kV}$; режим II: $3-40 \mathrm{kV}, 4-70 \mathrm{kV}$; режим III: $5-40 \mathrm{kV}, 6-70 \mathrm{kV}$. 
щем напряжении $70 \mathrm{kV}$ проявляется дополнительная полоса в области $410-420 \mathrm{~nm}$. Обнаружено, что при фокусировке пучка электронов (переход от эллиптического пятна к круглому размером $0.5 \mathrm{~mm}$ ) наблюдается усиление полосы с максимумом при $330 \mathrm{~nm}$, снижение интенсивности пика при $694 \mathrm{~nm}$, снижение интенсивности в области 600-1050 nm. В спектре КЛ, полученном в режиме II (рис. 2, $b$, кривые 3,4 ), полоса с максимумом при $330 \mathrm{~nm}$ подавлена и наблюдаются только полосы в длинноволновой области: узкий пик при $694 \mathrm{~nm}$, широкая полоса в области 600-1050 nm. Точно так же как и при съемке в режиме I, увеличение ускоряющего напряжения с 40 до $70 \mathrm{kV}$ приводит к усилению интенсивностей всех полос люминесценции. При этом замечено, что интенсивности полос при одинаковых ускоряющих напряжениях для чистой поверхности сапфира (съемка в режиме I) выше, чем для образца с пленкой $\mathrm{BaFe}_{12} \mathrm{O}_{19}$ (съемка в режиме II). Наиболее интересный результат был получен при исследовании спектров КЛ в режиме III (рис. 2, b, кривые 5,6). Исследовалась спектральная зависимость КЛ со стороны подложки при возбуждении люминесценции со стороны пленки. Наблюдались полосы свечения, аналогичные представленным в спектре КЛ образца подложки сапфира (режим I), однако интенсивность излучения полос в длинноволновой области была значительно выше и при ускоряющем напряжении $70 \mathrm{kV}$ достигала максимума в эксперименте. В то же время интенсивность свечения полосы с максимумом при $330 \mathrm{~nm}$ была значительно ниже. При увеличении ускоряющего напряжения до $70 \mathrm{kV}$ проявлялась полоса в области 410-420 nm.

Очевидно, отклонение пучка электронов в правый сектор дифракционной картины (рис. 2,a) связано с воздействием магнитного поля пленки $\mathrm{BaFe}_{12} \mathrm{O}_{19}$. Точно так же велика вероятность поглощения пленкой части электронов в результате многократных соударений в толще пленки и под воздействием магнитного поля. С этим может быть связано наблюдаемое в эксперименте снижение интегральной интенсивности свечения светочувствительной пластины электронографа.

В общем случае полоса в области $330 \mathrm{~nm}$ (рис. 2, $b$ ) традиционно связана с центрами окраски в сапфире $F^{+}$-типа (однократно заряженные вакансии кислорода [11]). Здесь следует отметить отсутствие на спектрах КЛ при ускоряющем напряжении $40 \mathrm{kV}$ (рис. 2, $b$, кривые 1,5$)$ полосы в области $410-420 \mathrm{~nm}$, связанной со свечением $F$-центров (вакансии кислорода, захватившие два электрона). При облучении электронами происходит подавление $F$-центров за счет образования новых $F^{+}$-центров согласно [11]:

$$
\begin{aligned}
F & + \text { excitation } \rightarrow\left(F^{+}\right)^{*}+e_{\text {trapped }}^{-} \rightarrow F^{+} \\
& +h v(330 \mathrm{~nm})+e_{\text {trapped }}^{-},
\end{aligned}
$$

где $\left(F^{+}\right)^{*}$ - возбужденный $F^{+}$-центр.

Как было обнаружено в экспериментах (рис. 2, $b$, кривые 2,6), полоса в области 410-420 nm проявляется при увеличении ускоряющего напряжения до $70 \mathrm{kV}$. Это может быть связано с нагревом, приводящим к освобождению глубоких ловушек электронов. В свою очередь, согласно [12], присутствие избыточного количества электронов предполагает возможность обратного перехода:

$$
F^{+}+e^{-} \rightarrow(F)^{*} \rightarrow F+h v(420 \mathrm{~nm}),
$$

где $(F)^{*}$ - возбужденный $F$-центр.

Узкий пик при $694 \mathrm{~nm}$ и широкая полоса в области 600-1050 nm связаны с переходами ${ }^{2} E-{ }^{4} A_{2}$ и ${ }^{2} E-{ }^{2} T_{2}[12]$ в примесных центрах $\mathrm{Cr}^{3+}$ и $\mathrm{Ti}^{3+}$ соответственно. Данные примеси традиционно присутствуют в выращенных кристаллах сапфира. Согласно проведенному анализу, присутствующие в исследованных образцах центры окраски связаны с сапфировой подложкой. Вообще говоря, спектр поглощения $\mathrm{BaFe}_{12} \mathrm{O}_{19}$ [13] в ультрафиолетовом и видимом диапазонах электромагнитных волн характеризуется значительным поглощением в области 200-600 nm, после чего коэффициент поглощения снижается в несколько раз. Эти данные свидетельствуют о возможном присутствии центров свечения в пленке $\mathrm{BaFe}_{12} \mathrm{O}_{19}$, которые накладываются на широкую полосу в длинноволновой области люминесценции в сапфире. Надежных исследований люминесцентных свойств $\mathrm{BaFe}_{12} \mathrm{O}_{19}$ в литературе не обнаружено, а имеющиеся единственные данные [14] свидетельствуют о присутствии полосы свечения с максимумом при $658 \mathrm{~nm}$ в легированных трехвалентными ионами гадолиния пленках. Значительное поглощение пленок $\mathrm{BaFe}_{12} \mathrm{O}_{19}$ в ультрафиолетовом диапазоне объясняет отсутствие $F^{+}$-полосы (рис. 2, $b$, кривые 3,4) и снижение интенсивности свечения в длинноволновой области на спектральной зависимости КЛ, полученной в режиме II (рис. 2, $b$, кривые 3,4$)$. Для сравнения в спектрах КЛ, полученных в режиме III (рис. 2, $b$, кривые 5,6 ), когда излучение не поглощается в пленке, интенсивность полос в длинноволновой области намного выше. При симметричном расположении входной группы спектрометра относительно плоскости подложки (режимы II, III) интенсивности и формы полос при одинаковых ускоряющих напряжениях должны быть близки. Это было ранее проверено на пленках $\mathrm{ZnO}$ на сапфире.

Сравнение интенсивностей полос КЛ с максимумом при $330 \mathrm{~nm}$ (кривые 1,6 и 2,5 на рис. 2,b) позволяет судить о преимущественной генерации кислородных вакансий в сапфире в процессе воздействия высокоэнергетическими электронами, нежели о перезарядке имеющихся кислородных вакансий. Это свидетельство того, что выращенные кристаллы сапфира не являются аниондефицитными. Интенсивности $F^{+}$-полосы в спектре КЛ чистой подложки сапфира (рис. 2, $b$, кривая 1) при $40 \mathrm{kV}$ и образца сапфира с пленкой при $70 \mathrm{kV}$ (рис. 2, $b$, кривая 6) близки. Присутствие пленки на поверхности сапфира тормозит процесс генерации кислородных вакансий. В то же время понятно, что 
увеличение энергии электронов позволяет генерировать кислородные вакансии в более глубоких слоях сапфира, увеличивая тем самым концентрацию $F^{+}$-центров при росте ускоряющего напряжения.

При фокусировке пучка электронов интенсивность $F^{+}$-полосы в сапфире должна расти за счет перегрева и резкого увеличения скорости генерации вакансий кислорода. В нашем эксперименте подобного явления обнаружено не было, что свидетельствует об отсутствии фокусировки пучка электронов магнитным полем пленки. Имеет место локальный нагрев в приповерхностных слоях сапфира за счет частичного поглощения электронов в толще пленки. Это отражается в уширении и длинноволновом смешении максимума полосы люминесценции (рис. 2, $b$ ), связанной с примесными центрами $\mathrm{Ti}^{3+}$. Этот эффект хорошо изучен, и даже предложены эмпирические закономерности для его описания [15]. Однако весьма неожиданным является значительное усиление интенсивности КЛ сапфира в длинноволновой области при нанесении пленки $\mathrm{BaFe}_{12} \mathrm{O}_{19}$. По всей видимости, в эксперименте не достигается температура гашения люминесценции. В [16] отмечается, что уже при температуре порядка $300^{\circ} \mathrm{C}$ происходит существенное гашение полос люминесценции, связанных с $\mathrm{Ti}^{3+}$. Следовательно, вместе с частичным поглощением электронов в пленке следует иметь в виду изменение плотности потока электронов, прошедших сквозь пленку. При прохождении сквозь магнитную пленку плотность потока электронов снижается. При малой плотности потока электронов вероятность возбуждения центров окраски возрастает. В этом случае центры окраски успевают релаксировать путем излучения фотонов, а сама величина интенсивности люминесценции линейно зависит от плотности потока. Если же плотность потока электронов высокая, возбуждение может теряться на ловушках и других паразитных центрах, вследствие чего интенсивность люминесценции снижается. Таким образом, присутствие пленки $\mathrm{BaFe}_{12} \mathrm{O}_{19}$ позволяет перераспределить люминесценцию в сапфире преимущественно в „красную“ область.

В работе приведены результаты исследования особенностей взаимодействия потока быстрых электронов с пленками $\mathrm{BaFe}_{12} \mathrm{O}_{19}$ на $c$-сапфире при применении методов дифракции быстрых электронов и катодолюминесценции. Обнаружено отсутствие дифракционной картины от пленки $\mathrm{BaFe}_{12} \mathrm{O}_{19}$, свидетельствующее о декогерентном воздействии магнитного поля пленки на падающий пучок электронов. Продемонстрировано отклонение пучка электронов магнитным полем пленки $\mathrm{BaFe}_{12} \mathrm{O}_{19}$. Результаты, полученные в работе, свидетельствуют об отсутствии фокусировки пучка электронов магнитным полем пленки. Точно так же сложно судить о спин-поляризованности прошедших сквозь пленку электронов. Однако в работе продемонстрировано уменьшение плотности потока электронов при прохождении сквозь пленку $\mathrm{BaFe}_{12} \mathrm{O}_{19}$, что приводит к перераспределению катодолюминесценции в сапфировой подложке преимущественно в „красную“ область. Излучения, связанного с самой пленкой $\mathrm{BaFe}_{12} \mathrm{O}_{19}$, в эксперименте не обнаружено.

\section{Финансирование работы}

Работа выполнена с использованием оборудования ЦКП ФНИЦ „Кристаллография и фотоника“ при поддержке Минобрнауки России (проект RFMEFI62119X0035) в рамках выполнения работ по государственным заданиям ФНИЦ „Кристаллография и фотоника“ РАН, а также при поддержке Российского фонда фундаментальных исследований (грант № 18-2912099 мк).

\section{Конфликт интересов}

Авторы заявляют, что у них нет конфликта интересов.

\section{Список литературы}

[1] R.C. Pullar, M.D. Taylor, A.K. Bhattacharya, J. Mater. Sci., 32, 349 (1997).

[2] W. Liu, J.Wu, Mater. Chem. Phys., 69, 148 (2001).

[3] J. Jalli, Y. Hong, G.S. Abo, S. Bae, J. Lee, J. Park, B.C. Choi, S. Kim, J. Magn. Magn. Mater., 32, 2627 (2011).

[4] Y.Y. Meng, M.H. He, Q. Zeng, D.L. Jiao, S. Shukla, R.V.Ramanujan, Z.W. Liu, J. Alloys Compd., 583, 220 (2014).

[5] Q.A. Pankhurst, R.S. Pollard, J. Phys.: Condens. Matter, 5, 5457 (1993).

[6] С.В. Труханов, А.В. Труханов, В.Г. Костишин, Л.В. Панина, И.С. Казакевич, В.О. Турченко, В.В. Кочервинский, Письма в ЖЭТФ, 103 (2), 106 (2016).

[7] S.B. Narang, I.S. Hudiara, J. Ceram. Proc. Res., 7, 113 (2006).

[8] A. Kumar, V. Agarwala, D. Singh, Progr. Electromagn. Res., 29, 223 (2013).

[9] А.В. Буташин, В.П. Власов, В.М. Каневский, А.Э. Муслимов, В.А. Федоров, Кристаллография, 57 (6), 927 (2012).

[10] А.В. Буташин, А.Э. Муслимов, В.М. Каневский, А.Н. Дерябин, В.А. Павлов, В.Е. Асадчиков, Кристаллография, 58 (3), 473 (2013).

[11] M. Ghamnia, C. Jardin, M. Bouslama, J. Electron Spectrosc. Relat. Phenom., 133, 55 (2003).

[12] V.B. Mikhailik, P.C.F. Di Stefano, S. Henry, H. Kraus, A. Lynch, V. Tsybulskyi, M.A. Verdier, J. Appl. Phys., 109, 053116 (2011).

[13] S. Wang, H. Gao, G. Sun, J. Zhang, Y. Xia, C. Xie, G. Yang, Y. Wang, L. Fang, J. Clust. Sci. (2020). https://doi.org/10.1007/s10876-020-01815-6

[14] J. Mahapatro, S. Agrawal, IOP Conf. Ser.: Mater. Sci. Eng., 798, 012011 (2020).

[15] H. Burton, C. Debardelaben, W. Amir, T.A. Planchon, Opt. Express, 25, 6954 (2017).

[16] J.Drabik, B. Cichy, L. Marciniak, J. Phys. Chem. C, 122, 14928 (2018). 